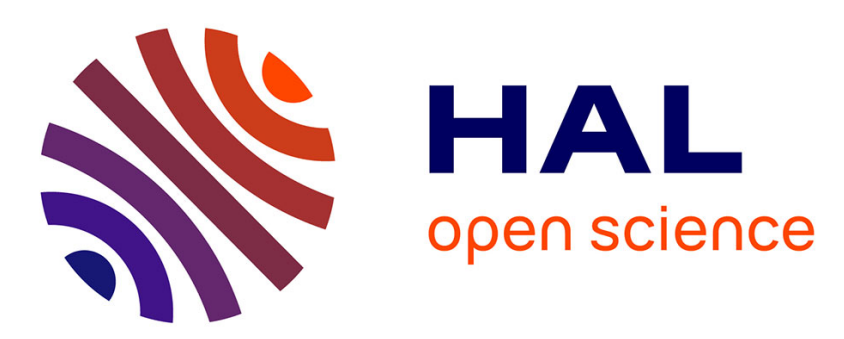

\title{
Full field monitoring of the resin flow and laminate properties during the resin infusion process
}

\author{
Quentin Govignon, S. Bickerton, J. Morris, P.A. Kelly
}

\section{To cite this version:}

Quentin Govignon, S. Bickerton, J. Morris, P.A. Kelly. Full field monitoring of the resin flow and laminate properties during the resin infusion process. Composites Part A: Applied Science and Manufacturing, 2008, 39 (9), pp.1412-1426. 10.1016/j.compositesa.2008.05.005 . hal-02070810

\section{HAL Id: hal-02070810 https://hal.science/hal-02070810}

Submitted on 29 Nov 2019

HAL is a multi-disciplinary open access archive for the deposit and dissemination of scientific research documents, whether they are published or not. The documents may come from teaching and research institutions in France or abroad, or from public or private research centers.
L'archive ouverte pluridisciplinaire HAL, est destinée au dépôt et à la diffusion de documents scientifiques de niveau recherche, publiés ou non, émanant des établissements d'enseignement et de recherche français ou étrangers, des laboratoires publics ou privés. 


\title{
Full field monitoring of the resin flow and laminate properties during the resin infusion process
}

\author{
Q. Govignon ${ }^{\mathrm{a}}$, S. Bickerton ${ }^{\mathrm{a}, *}$, J. Morris ${ }^{\mathrm{b}}$, P.A. Kelly ${ }^{\mathrm{c}}$ \\ ${ }^{a}$ Centre for Advanced Composite Materials, Department of Mechanical Engineering, The University of Auckland, Private Bag 92019, Auckland, New Zealand \\ ${ }^{\mathrm{b}}$ Communication and Information Technology Research, Department of Computer Science, The University of Auckland, Private Bag 92019, Auckland, New Zealand \\ ${ }^{\mathrm{c}}$ Centre for Advanced Composite Materials, Department of Engineering Science, The University of Auckland, Private Bag 92019, Auckland, New Zealand
}

\begin{abstract}
A B S T R A C T
The resin infusion process (a.k.a. VARTM, SCRIMP) has developed as a low cost method for manufacturing large fibre reinforced plastic parts. This process still presents some challenges to industry with regards to reliability and repeatability, resulting in trial and error development being expensive and inefficient. This paper describes a fully instrumented resin infusion setup, providing preliminary experimental data acquired while varying influential parameters during the filling and post-filling stages. The laminate permeability is a strong function of the fibre volume fraction which can be determined from the laminate thickness. To assess the variation of the volume fraction and permeability, full field thickness variations have been monitored using a digital speckle stereophotogrammetry system developed for this purpose. In-mould resin pressures, flow front progression, and incoming resin flow rate were also measured. A selection of four experiments is presented here for discussion.
\end{abstract}

Resin infusion

B. Physical properties

B. Porosity

D. Process monitoring

\section{Introduction}

Resin infusion (RI) is part of the liquid composite moulding (LCM) process family. The term LCM describes the closed mould processes in which a liquid polymeric resin is impregnated through a fibrous reinforcement. Common LCM processes are resin transfer moulding (RTM), injection/compression moulding (I/CM), RTM light and resin infusion (RI). LCM processes provide good control over harmful volatiles generated by thermoset resins, making them compliant with tougher new environmental standards put in place internationally. The final fibre volume fraction $\left(V_{\mathrm{f}}\right)$ achieved can be higher and more consistent than with more traditional open mould techniques. LCM processes also have potential for automation, greatly reducing labour costs $[1,2]$.

Fig. 1 describes the different components required for application of RI, and the different process stages. Initially, layers of fibrous reinforcement are laid on the mould to form the preform. Peel ply is then laid over the preform, allowing for easy separation of the consumables from the part, and a reasonable surface on the side of the part not in contact with the mould. Distribution media can be laid over the peel ply to enhance resin flow if the preform has low in-plane permeability. Once inlet and vent tubes are placed, the mould is closed using a vacuum bag sealed with sealant tape. With the cavity sealed, the inlet is clamped and vacuum is applied to the vents, this stage being referred to here as "pre-

\footnotetext{
* Corresponding author. Tel.: +64 9373 7599x88194; fax: +64 93737479

E-mail address: s.bickerton@auckland.ac.nz (S. Bickerton).
}

filling". At the end of pre-filling, the inlet is opened and the resin penetrates the preform. During the "filling stage", pressure inside the cavity varies in position and time. From the vent to the flow front, pressure is equal to the vacuum pressure at the vents. Within the impregnated portion of the preform the resin pressure varies from vacuum at the flow front to near atmospheric pressure at the inlet. Once the resin front reaches the end of the preform, the inlet is usually clamped. The "post-filling" stage involves removal of excess resin, and allows resin pressure to equilibrate within the cavity. Once the resin is fully cured, the vacuum is released and the part is lifted off the mould and separated from the consumables.

During processing, the operator typically has little control over the advancement of the flow front, and process development by trial and error can be long and expensive. Reduction development costs requires a good understanding of the process physics, and development of an accurate simulation tool. Significant effort has been put into developing RTM simulations that accurately predict fill times and flow front advancement [3-9]. As the vacuum bag employed during RI provides minimal rigidity, the preform thickness will vary in relation to the resin pressures inside the cavity [10-13], as will the local permeability. Increasing resin pressure inside the cavity reduces the compaction stress on the preform, affecting local $V_{\mathrm{f}}$ and permeability. An accurate simulation of RI therefore needs to include a comprehensive reinforcement compaction model for both dry and wet states [9,14-18], and account for preform thickness changes. This will allow for greater accuracy during filling, and the ability to predict the final $V_{\mathrm{f}}$ of the laminate. 


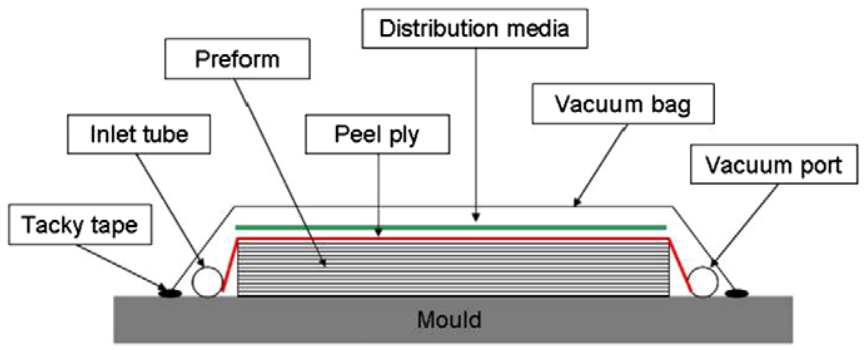

(a) Lay up

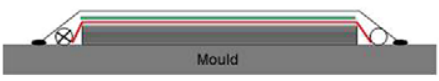

(b) Pre-filling

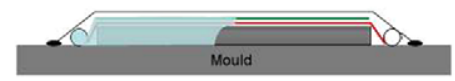

(c) Filling

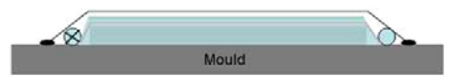

(d) Post-filling

Fig. 1. Stages in the resin infusion process.

This paper describes the experimental program established in order to verify an RI simulation under development. Resin pressures inside the laminate as well as the flow rate into the laminate, the laminate thickness and the flow front velocity are recorded. A stereophotogrammetry system has been developed which provides full field laminate thickness measurements. This system produces a resolution of $0.001 \mathrm{~mm}$ for a measurement field of 800 by $600 \mathrm{~mm}$, capturing data every $5 \mathrm{~s}$. Several demonstration experiments are presented, providing some insight into influential factors such as resin viscosity, the presence of distribution media, and style of reinforcement.

\section{Theory}

\subsection{Stereophotogrammetry}

The thickness measurement technique used here is based on speckle photogrammetry [19-21], the idea being to compare a pattern on an object surface before and after deformation. The stereo version of this technique allows for out-of-plane deformation measurement, and reduces problems with perspective errors. Before deformation, a pair reference images were taken by a pair of cameras, and a set of correspondences were established. During deformation, two sequences of images were taken. The relative displacements to the reference images were calculated on a leftleft and right-right comparison basis. Having collected all the initial states and the displacement vectors, the 3D deformations were calculated by triangulating corresponding pairs formed by their initial positions plus displacement vectors.

\subsubsection{Matching of the measurement points}

The technique applied here records only the displacement vector. For triangulation, the initial coordinates in the left and right reference images must be established. Since the focus is on thickness variation and laminate stacking is uniform across the surface, the initial vacuum bag surface can be approximated as a plane due to its dimension compared to the diameter of the fibre tows. Thus correspondences at the initial stage can be approximated as a planar homography, $\mathrm{H}$, a $3 \times 3$ matrix:

$x^{\prime}=H x$,

where $x$ and $x^{\prime}$ are a pair of corresponding points in the left and right images respectively. Given coordinates of at least four pairs of corresponding points, the planar homography can be found by direct linear transformation or other methods. Once the planar homography is known, a set of points $P_{i, j}$ is chosen in the left image and the corresponding points are determined in the right image. Fig. 2 shows a pair of images with 200 measurement points superimposed on the laminate. For this paper, points were taken every $4 \mathrm{~mm}$ along the length, and every $25 \mathrm{~mm}$ across the width.

\subsubsection{In-plane displacement measurement}

Given a unique pattern on an object surface, the corresponding region in a subsequent image can be found by cross correlation of the original pattern with the subsequent image. Consider matching a pattern $w(x, y)$ of size $J \times K$ in an image, with $f(x, y)$ of size $M \times N$ in the subsequent image. The correlation between $w(x, y)$ and $f(x, y)$ is

$c(s, t)=\sum_{x=0}^{J-1} \sum_{y=0}^{K-1} f(x, y) w(x-s, y-t)$
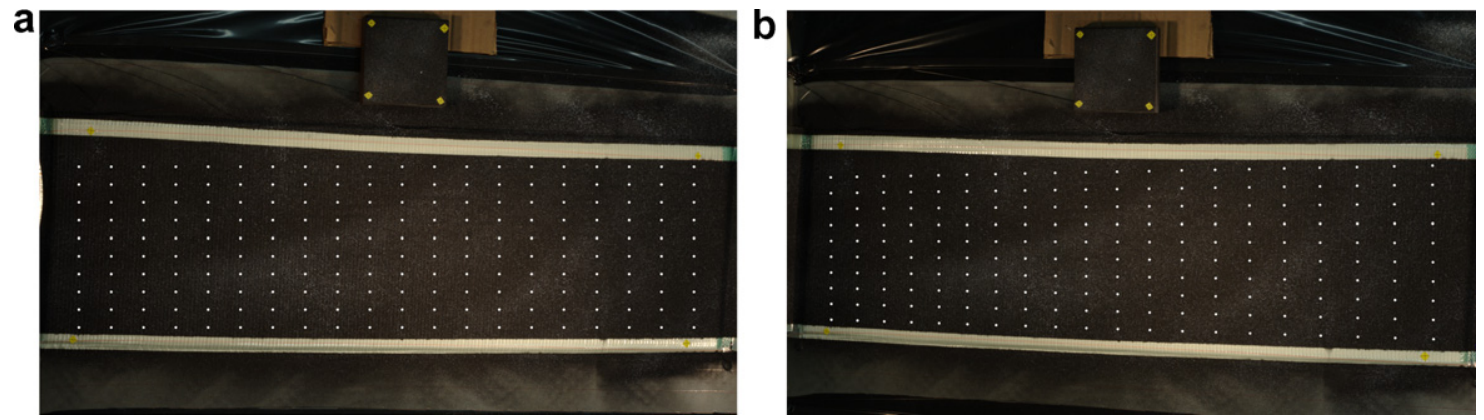

Fig. 2. Example of points registration on a pair of (a) left and (b) right images. 


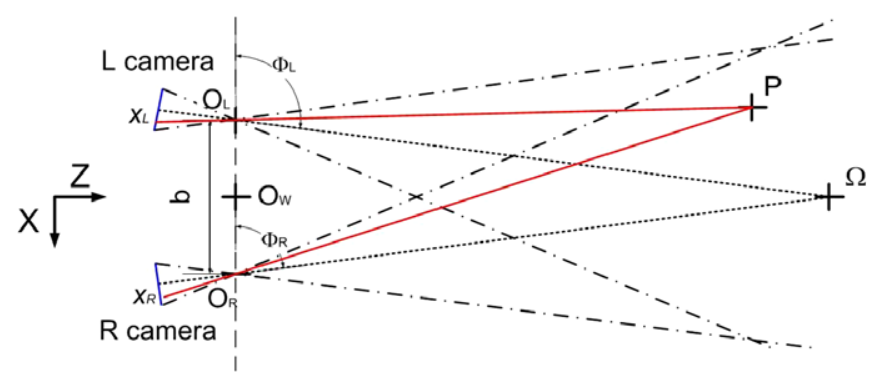

Fig. 3. Definition of parameters for the stereophotogrammetry technique. where $s=0,1,2, \ldots, M-1, t=0,1,2, \ldots, N-1$. The position of the maximal value in $c(s, t)$ indicates where $w(x, y)$ matches $f(x, y)$. The correlation can be computed in the frequency domain if $f$ and $w$ have the same size (i.e. when $M=J$ and $N=K$ ). Then:

$f(x, y) \circ w(x, y) \Longleftrightarrow F^{*}(u, v) W(u, v)$,

where $f(x, y) \circ w(x, y)$ denotes the correlation between $f(x, y)$ and $w(x, y)$, and $F(u, v)$ and $W(u, v)$ are the Fourier transforms (FT) of $f(x, y)$ and $w(x, y)$. Eq. (4) shows that the correlation in the spatial domain can be obtained by taking the inverse transform of $F^{*}(u, v)$ $W(u, v)$ in the frequency domain:

$c(s, t)=F^{-1}\left\{F^{*}(u, v) W(u, v)\right\}$,

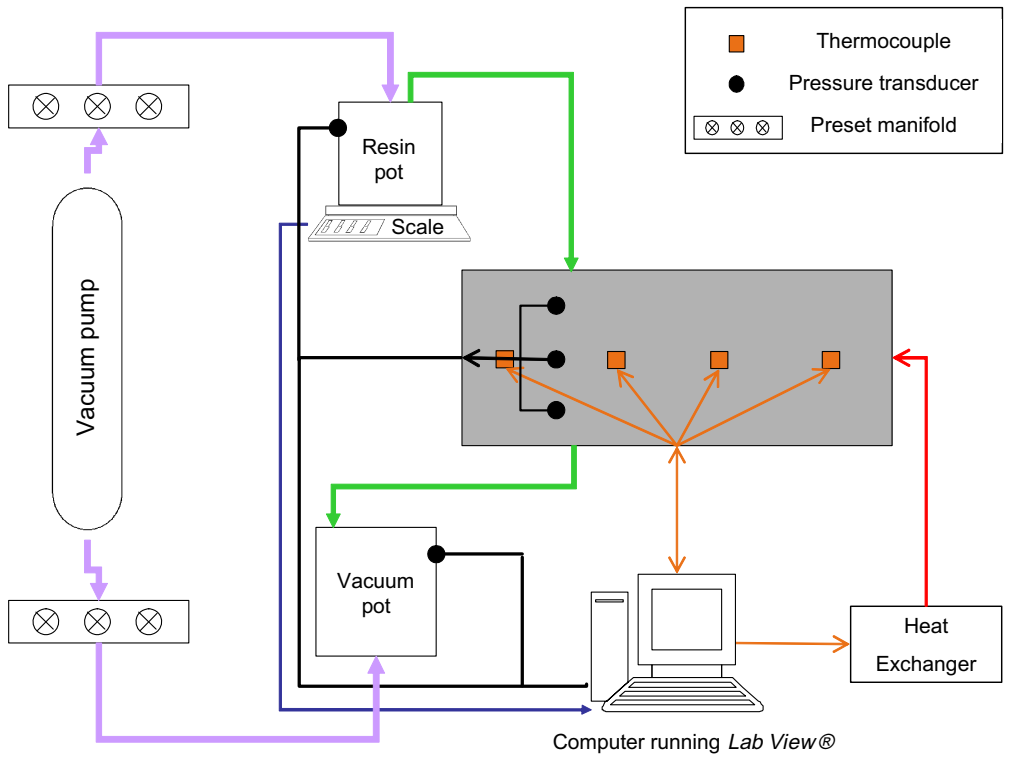

Fig. 4. Schematic of the data acquisition setup.

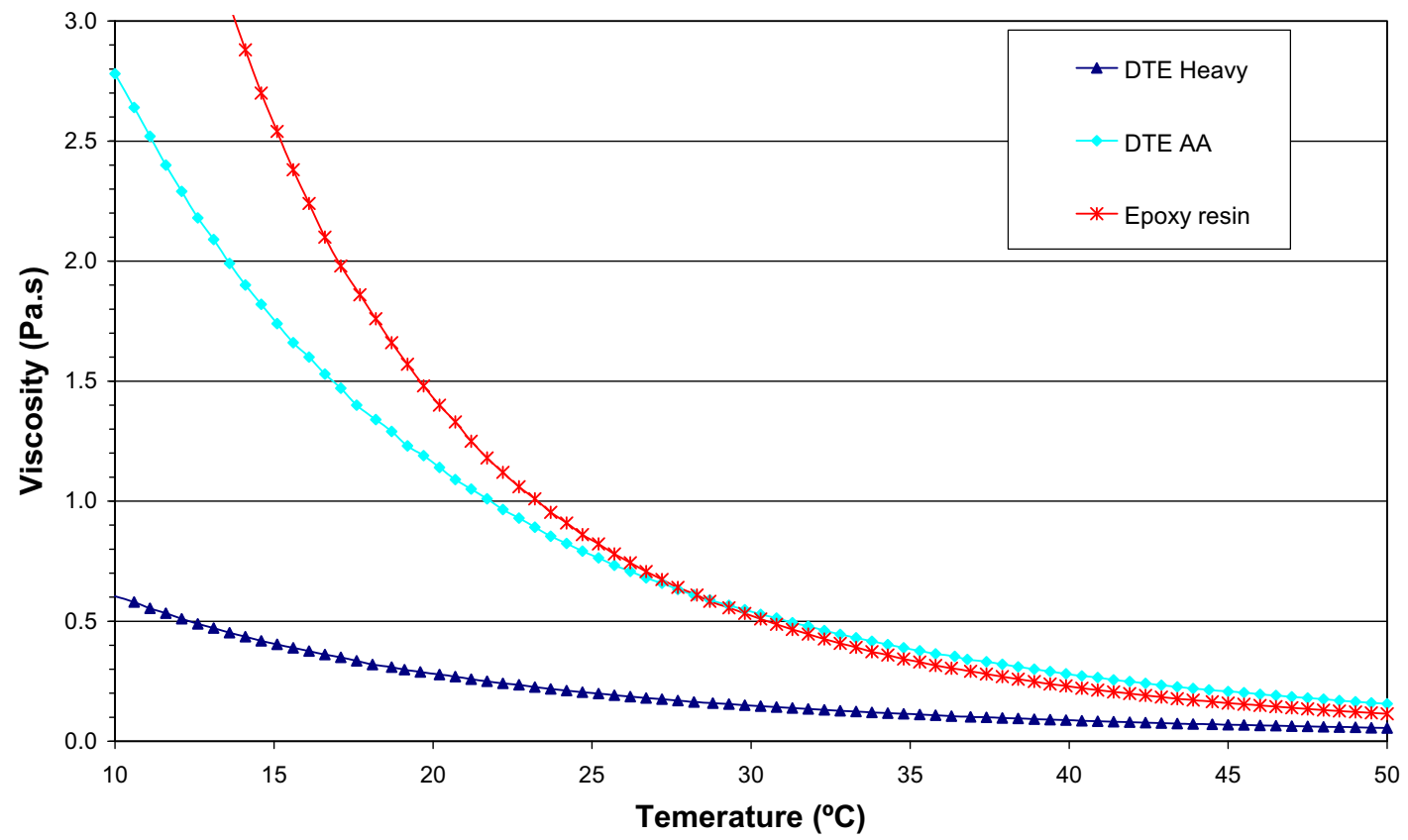

Fig. 5. Viscosity of the test fluid and the Nuplex R300 epoxy resin as a function of temperature. 


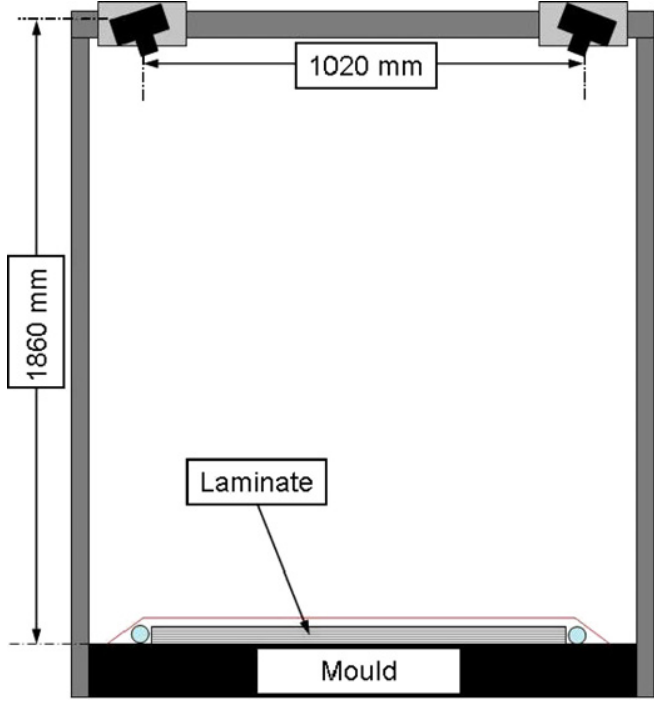

Fig. 6. Schematic of the mounting frame for the stereophotogrammetry system.

where $F^{-1}$ is the inverse FT operator. In general the translation will be non-integral, a 2D parabola plotted to the surrounding nine points to estimate a sub-pixel translation value.
The random error in locating the correlation peak is [22]:

$e=k \zeta 2 \sqrt{\frac{1-\delta}{\delta}}$

where $\delta$ is the correlation factor, $\zeta$ is the average speckle size, and $k$ is a function of $\zeta$ and the inverse of the window size. The accuracy drops quickly as the correlation drops. If there is a large displacement between two fields, the correlation function will have a smeared out peak because of the decreased correlation (less overlapping area). In such cases, for the biggest possible overlapping area, the position of the window will be shifted to the new position until the integral translation is zero. The sub-pixel peak position is then estimated after this shift. Centering the patterns on the points $P_{i, j}$ enables mapping of the displacement of the $P_{i, j}$ in both the left and right image sequence, and subsequent calculation of the image coordinates of $P_{i, j}$ in every image.

\subsubsection{Deformation calculation}

Once the image coordinates of the points $P_{i, j}$ in the initial and following images are known, normal stereophotogrammetry and triangulation techniques are used to determine point positions in the global coordinates. With calibrated stereo cameras, the position of a scene point can be obtained by intersecting two rays formed by the corresponding points in the left and right images (see Fig. 3). From calibration, the distance $b$, separating the optical

\section{a}

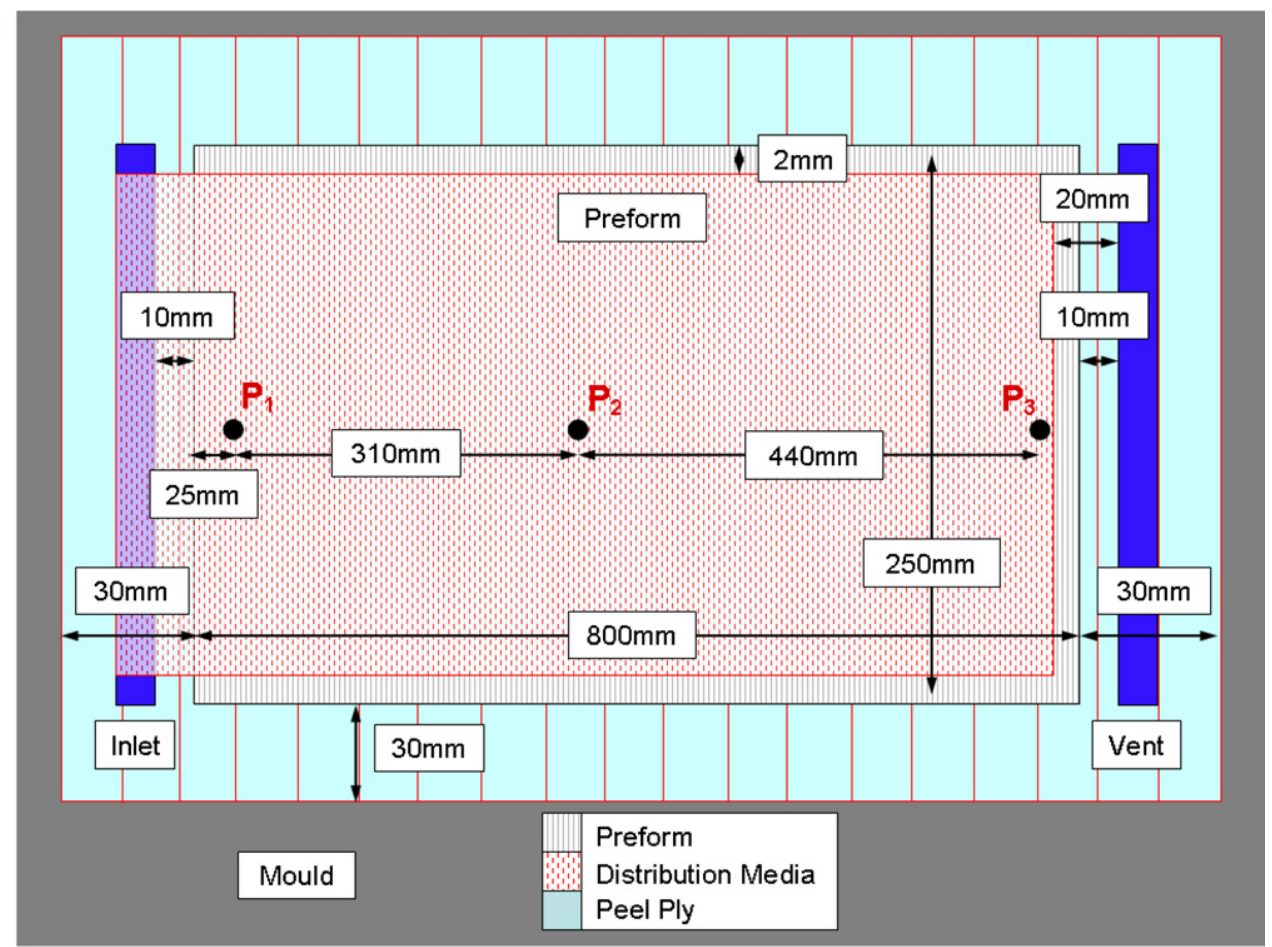

b

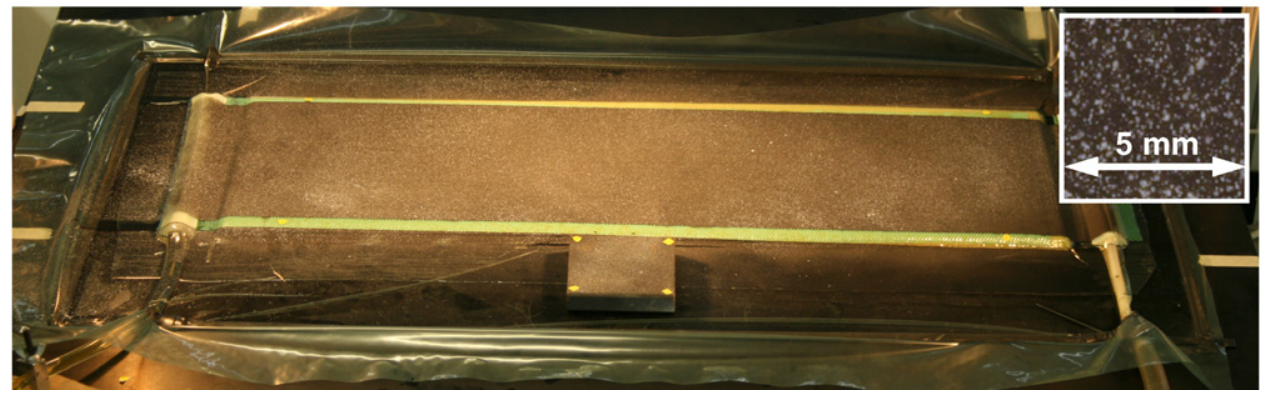

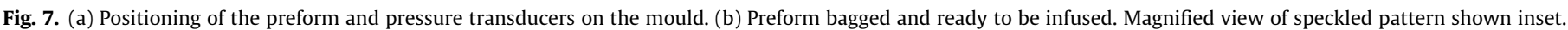


centres $\mathrm{O}_{L}$ and $\mathrm{O}_{R}$ of the left and right camera, respectively, is calculated as well as the angles $\phi_{\mathrm{L}}$ and $\phi_{\mathrm{R}}$ between the base line and the optical axes of respectively the left and right camera. The optical axes intersect at the fixation point $\Omega$. A point $P\left(X_{P}, Y_{P}, Z_{P}\right)$, appears at $\left(x_{\mathrm{L}}, y_{\mathrm{L}}\right)$ in the left camera image and $\left(x_{\mathrm{R}}, y_{\mathrm{R}}\right)$ in the right camera image. If global coordinates are referenced to an origin, $\mathrm{O}_{\mathrm{w}}$ (mid-point of the baseline joining the two camera optical centres) and axes $X, Y$ and $Z$ as shown in Fig. 3, then the coordinates of the point $P$ are:

$X_{P}=\frac{b}{2} \frac{\left(f \tan \phi_{\mathrm{R}}+x_{\mathrm{R}}\right)\left(f-\tan \phi_{\mathrm{L}} x_{\mathrm{L}}\right)+\left(f \tan \phi_{\mathrm{L}}+x_{\mathrm{L}}\right)\left(f-\tan \phi_{\mathrm{R}} x_{\mathrm{R}}\right)}{\left(f \tan \phi_{\mathrm{R}}+x_{\mathrm{R}}\right)\left(f-\tan \phi_{\mathrm{L}} x_{\mathrm{L}}\right)-\left(f \tan \phi_{\mathrm{L}}+x_{\mathrm{L}}\right)\left(f-\tan \phi_{\mathrm{R}} x_{\mathrm{R}}\right)}$

$Z_{P}=-\left(\frac{b}{2}+X_{P}\right) \frac{f \tan \phi_{\mathrm{L}}+x_{\mathrm{L}}}{f-\tan \phi_{\mathrm{L}} x_{\mathrm{L}}}$

$Y_{P}=\frac{Z}{f \sin \phi_{\mathrm{L}}} y_{\mathrm{L}}$,

where $f$ is the focal length. For the speckle stereophotogrammetry technique, the initial points $P_{i, j}$ are arbitrarily chosen and defined as being at a $Z=0$. The positions of the points after deformation are calculated compared to the initial map. In other words, the system can only extract laminate thickness variation instead of actual thickness. The initial laminate thickness was measured prior to the filling stage using a dial gauge.

\subsection{Relating volume fraction and permeability}

Assuming minimal porosity, laminate $V_{\mathrm{f}}$ can be determined by measuring local thickness and subsequently applying Eq. (9). This approach allows for a dynamic estimation of the changes in $V_{\mathrm{f}}$ and permeability during filling and post-filling.
$V_{\mathrm{f}}=\frac{N \cdot W}{\rho_{\mathrm{f}} \cdot h}$.

$N$ is the number of layers in the preform, $W$ is the mass of the reinforcing fabric per unit area, $\rho_{\mathrm{f}}$ is the density of the fibre material, and $h$ is the measured thickness of the laminate. For any given reinforcement, permeability is strongly dependant on the local $V_{\mathrm{f}}$. The relationship between permeability and $V_{\mathrm{f}}$ can be expressed using semi-empirical expressions such as the modified Carman-Kozeny equation [10]:

$K=\frac{d^{2}}{16 \cdot k} \cdot \frac{\left(1-V_{\mathrm{f}}\right)^{n+1}}{V_{\mathrm{f}}^{n}}$,

where $d$ is the fibre diameter, $n$ and $k$ are the dimensionless Kozeny constant found experimentally. This strong dependency of permeability on $V_{\mathrm{f}}$ highlights the need to closely monitor compaction of the reinforcement during both experiment and simulation.

\section{Experimental Facilities}

The experimental facilities were developed to closely monitor the RI process and gather data for comparison to simulation. A schematic of the setup is depicted in Fig. 4.

\subsection{Temperature control}

It is very important to be able to control laminate temperature in order to minimise viscosity variation, and to increase experimental repeatability. The viscosity data presented in Fig. 5 has been obtained using a Physica UDS200 cone-plate

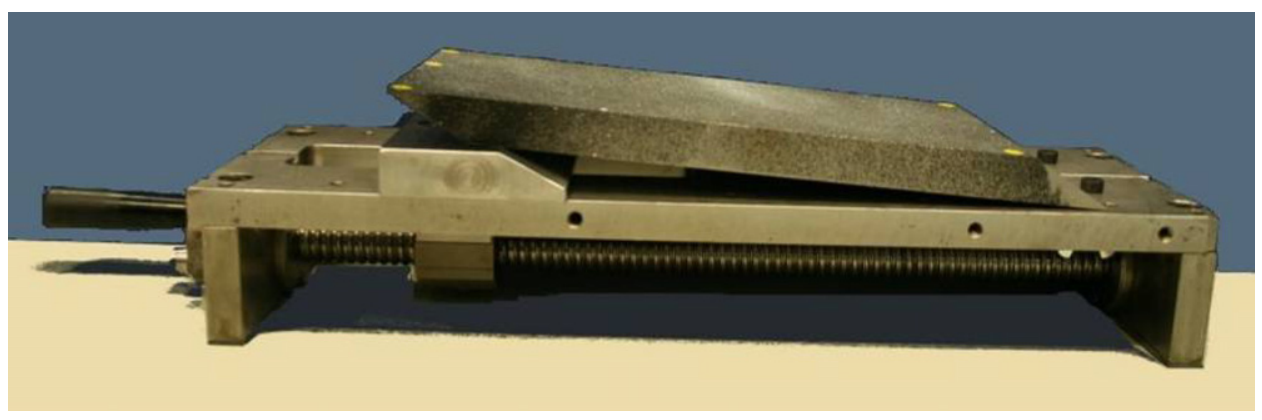

Fig. 8. Stereophotogrammetry calibration rig.

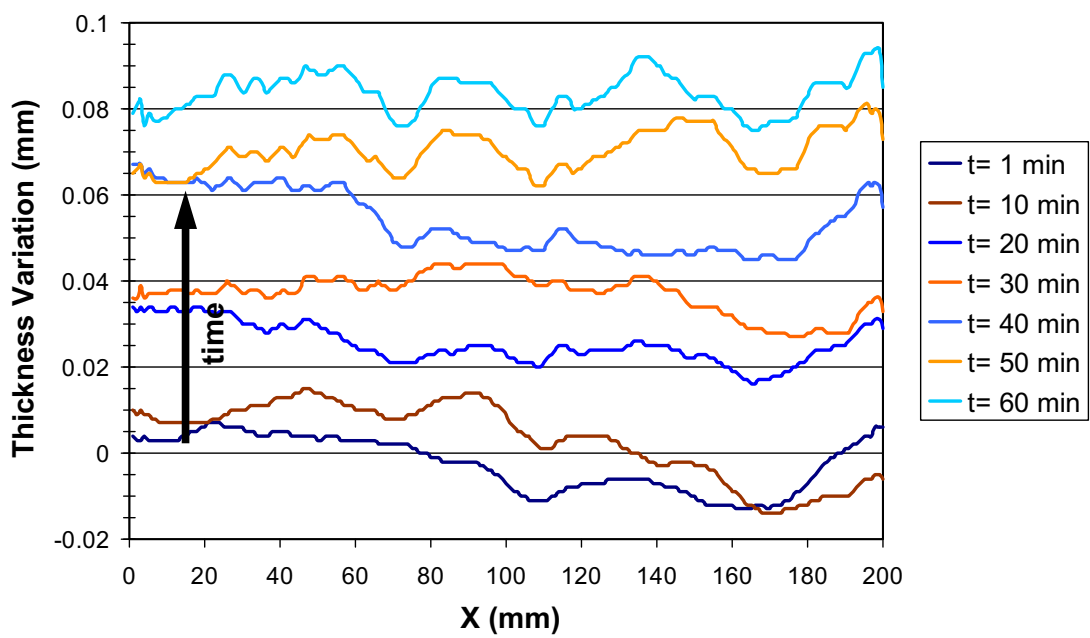

Fig. 9. Noise and thermal drift in thickness measurements over the stationary plate. 


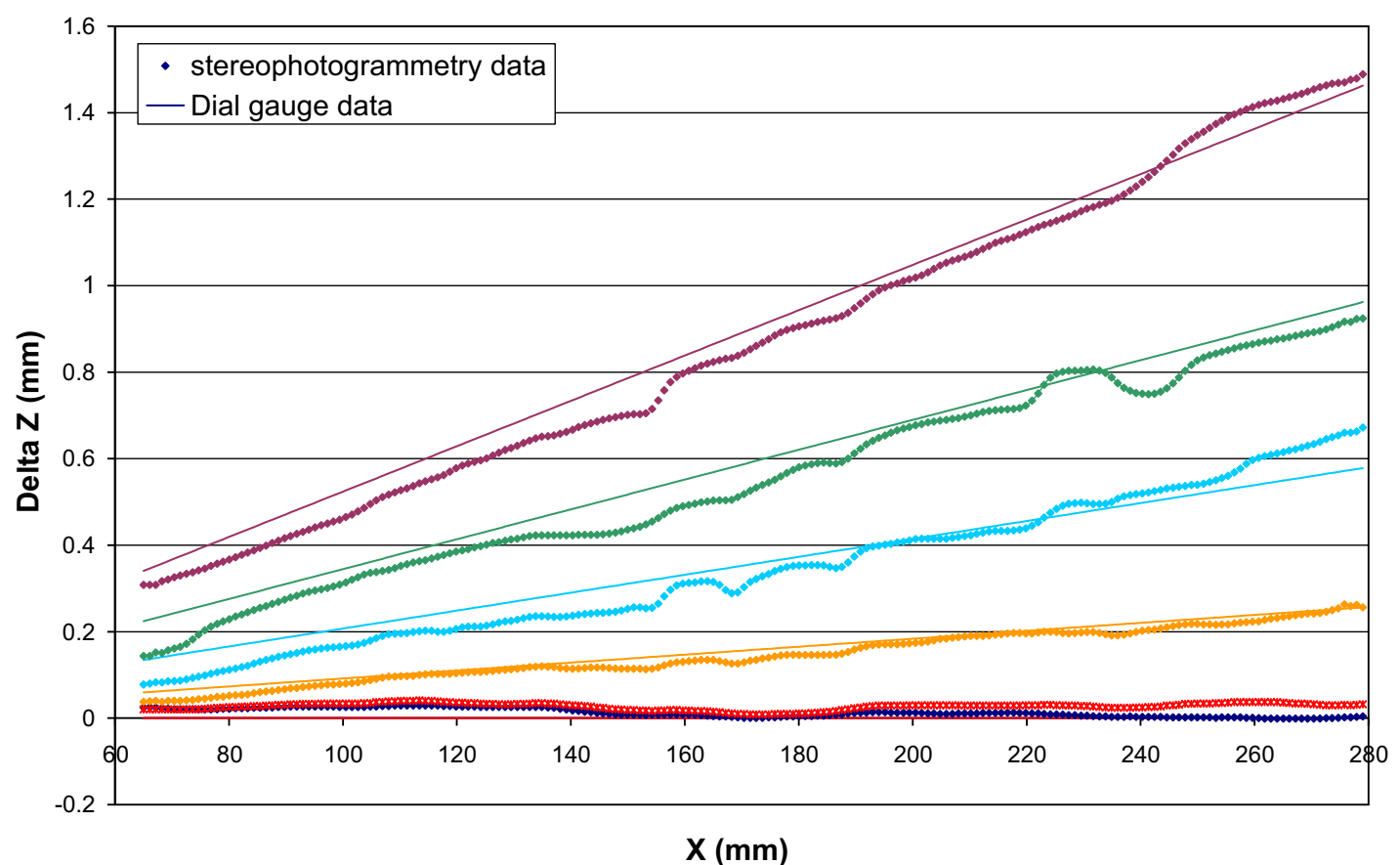

Fig. 10. Thickness measurement on the calibration rig.

$\left(50 \mathrm{~mm}, 1^{\circ}\right)$ rheometer. Measurements were made on the two mineral oils used in this study, and a typical infusion grade epoxy without hardener added (at a shear rate of $20 \mathrm{~s}^{-1}$, ramping temperature from 10 to $50^{\circ} \mathrm{C}$ ), demonstrating the significant influence of temperature.

A temperature controlled RI table has been developed, utilising a sandwich structure of $5 \mathrm{~mm}$ thick aluminium at the mould surface, $50 \mathrm{~mm}$ of PVC foam core, and $3 \mathrm{~mm}$ of aluminium at the lower skin. Copper tubes run just below the mould surface, circulating water supplied by a Boe-Therm Temp 95 vac thermolator. The temperature is monitored and controlled using thermocouples embedded in the mould and a computer running LabView. The table is able to run at temperatures between $20^{\circ} \mathrm{C}$ and $50{ }^{\circ} \mathrm{C}$, and has been maintained at $30^{\circ} \mathrm{C}$ throughout this study.

\subsection{Pressure measurement and control}

Resin pressure within the laminate can be measured at three points at the mould surface. The laminate layout is described in Fig. 7a, which also shows positioning of the three PMA P41 pressure transducers. A Terranova T926 gauge monitors the pressure inside the vacuum pot, and the atmospheric pressure is measured during each experiment. Two manifolds with preset valves enable control of the pressure within the vacuum pot and the resin pot. In this study the experiments were limited to full vacuum at the vacuum pot for both the filling and post-filling stages, and atmospheric pressure at the resin pot for the filling period. The inlet was clamped at the end of the filling stage.

\subsection{Laminate thickness measurement}

During pre-filling, pressure inside the laminate is equal to that within the vacuum pot, compaction stress applied to the laminate being equal to the difference between atmospheric and the vacuum pot pressure. As the cavity fills with resin, resin pressure inside the cavity increases, reducing the compaction stress on the preform, resulting in variation in laminate thickness. During the post-filling period, as the resin pressures inside the laminate decrease and equilibrate, compaction of the preform increases $[23,24]$. It has been demonstrated that fibrous reinforcements have complex compaction behaviour, exhibiting visco-elasticity and permanent deformation [25-34]. These materials can also display a change in the rigidity between the dry and saturated state $[33,35,36]$.

Previous researchers have monitored laminate thickness variation using dial gauges or laser transducers $[23,37,38]$. However dial gauges and LVDTs are contact measurements, and the pressure applied on the laminate were deemed non-negligible for the accuracy desired in this study. Laser gauges were initially employed in this research programme, as they provide the advantage of being contact free. However, problems caused by the uneven and reflective surface of the plastic bag resulted in unacceptable noise levels. These initial measurements did demonstrate that thickness changes were significant enough to influence local reinforcement permeability, therefore emphasizing the need for more extensive measurements.

\subsubsection{Setup}

The developed stereophotogrammetry system provides a contact free, full field measurement of laminate thickness variation

Table 1

Plan of experiments

\begin{tabular}{llll}
\hline Experiment & Reinforcement & $\begin{array}{l}\text { Distribution } \\
\text { media }\end{array}$ & Fluid \\
\hline 1 & $\begin{array}{l}800 \mathrm{~g} / \mathrm{m}^{2} \text { biaxial stitched } \\
\text { fabric }\end{array}$ & No & Mobil DTE AA \\
2 & $\begin{array}{l}800 \mathrm{~g} / \mathrm{m}^{2} \text { biaxial stitched } \\
\text { fabric }\end{array}$ & No & Mobil DTE \\
& $\begin{array}{l}800 \mathrm{~g} / \mathrm{m}^{2} \text { biaxial stitched } \\
\text { fabric } \\
480 \mathrm{~g} / \mathrm{m}^{2} \text { continuous filament } \\
\text { mat }\end{array}$ & Yes & $\begin{array}{l}\text { Heavy } \\
\text { Mobil DTE AA }\end{array}$ \\
4 & & & Mobil DTE AA \\
\hline
\end{tabular}


Table 2

Experimental results

\begin{tabular}{lllll}
\hline Experiment & 1 & 2 & 3 & 4 \\
\hline Initial thickness $(\mathrm{mm})$ & 6.062 & 6.03 & 6.031 & 9.55 \\
Initial $\mathrm{V}_{\mathrm{f}}$ & 0.462 & 0.463 & 0.465 & 0.234 \\
Final $\mathrm{V}_{\mathrm{f}}$ & 0.475 & 0.481 & 0.47 & 0.284 \\
Fill time (min) & 170 & 53 & 62 & 27.5 \\
\hline
\end{tabular}

[20,21]. The system uses two high resolution digital cameras (Canon EOS20D, 8Mpixel, $f=50 \mathrm{~mm}$ lens) fixed on a rigid frame above the mould, converging over the preform surface. Care must be taken to minimise vibration or movement of the cameras, in order to reduce the errors incurred in an experiment in which thickness changes are typically below $1.0 \mathrm{~mm}$. The cameras are mounted at a height of $1860 \mathrm{~mm}$ on an aluminium frame. The cameras are
$1020 \mathrm{~mm}$ apart (shown schematically in Fig. 6), converging their field of view on the laminate.

The vacuum bag is painted with a high frequency random pattern (Fig. 7b) in order to assist image recognition. High average spatial frequency, i.e. a fine speckle pattern, is the critical characteristic: see Eq. (5). Small 'blobs' of colour are tolerated, but the pattern must not have low frequency components (i.e. any homogeneity). Four markers are placed on the bag to allow for manual image correspondence registration. Each camera is connected to a computer, and the two computers are networked to allow synchronisation of image acquisition. Using this system, images can be recorded at a rate of up to one image every $5 \mathrm{~s}$. The image acquisition software is triggered through LabView thus enabling, after post-treatment of the images, correlation between the thickness changes, flow front position, pressure, and flow rate measurements.
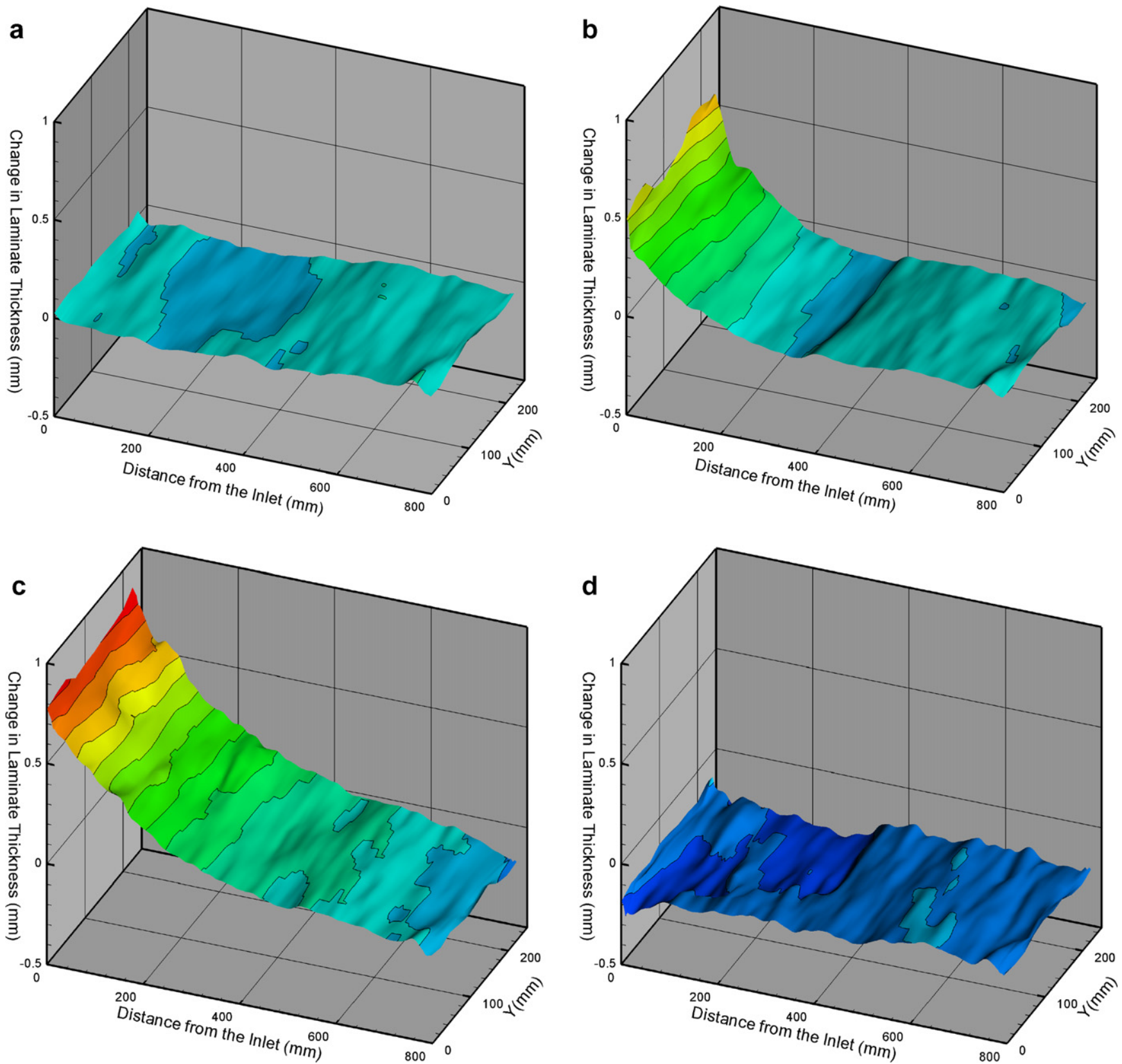

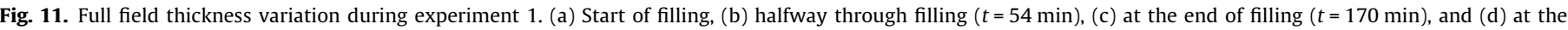
completion of post-filling $(t=340 \mathrm{~min})$. 

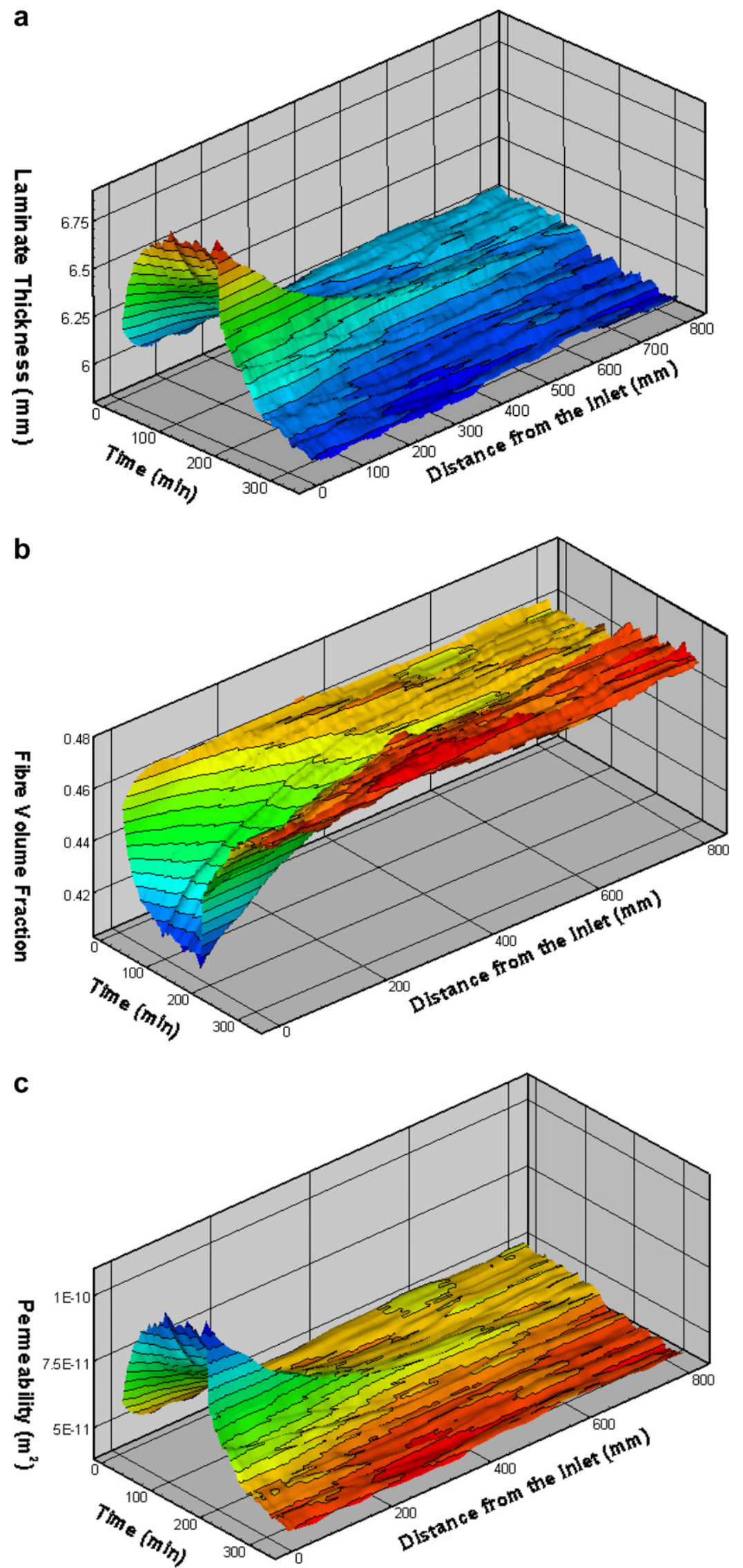

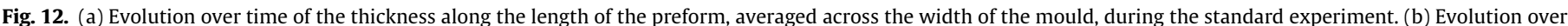
time of the $V_{f}$ along the length of the preform. (c) Evolution over time of in-plane permeability along the length of the preform. 


\subsubsection{Calibration}

A rig has been developed to calibrate the stereophotogrammetry system and verify its accuracy (see Fig. 8). A steel plate, $290 \mathrm{~mm}$ long, $130 \mathrm{~mm}$ wide and $20 \mathrm{~mm}$ thick, is cut at a $30^{\circ}$ angle at both ends and is painted on the top surface with a high frequency random pattern. A wedge mounted on a linear translation screw is used to raise and lower one end of the plate. A dial gauge measures displacement of one point on the plate, enabling calculation of the whole surface displacement. An initial series of images were recorded while keeping the plate stationery, in order to determine measurement noise. Fig. 9 presents thickness variation along the centreline of the plate, at seven instants over $1 \mathrm{~h}$. The maximum standard deviation at any instant is $0.014 \mathrm{~mm}$., the variations being due to a combination of small vibrations in the mounting frame, and unavoidable errors generated during the image recognition process. The observed drift with time is most likely due to thermal contraction in the camera mounting frame. With a thermal expansion coefficient of $2.36 \times 10^{-5}{ }^{\circ} \mathrm{C}^{-1}$, a $2{ }^{\circ} \mathrm{C}$ variation will cause a change of $0.087 \mathrm{~mm}$ to the length of the aluminium uprights. To eliminate this effect, a stationary plate was placed in the view field of the cameras during the RI experiments (see Fig. 7b). The thermal drift was monitored and deducted from the measured thickness variation.

A second test was completed while changing the orientation of the flat plate. Fig. 10 presents the comparison between the stereophotogrammetry data and position measured using the dial gauge. The average deviation from to the theoretical measurement was $0.04 \mathrm{~mm}$. Given these results, we will consider an accuracy of

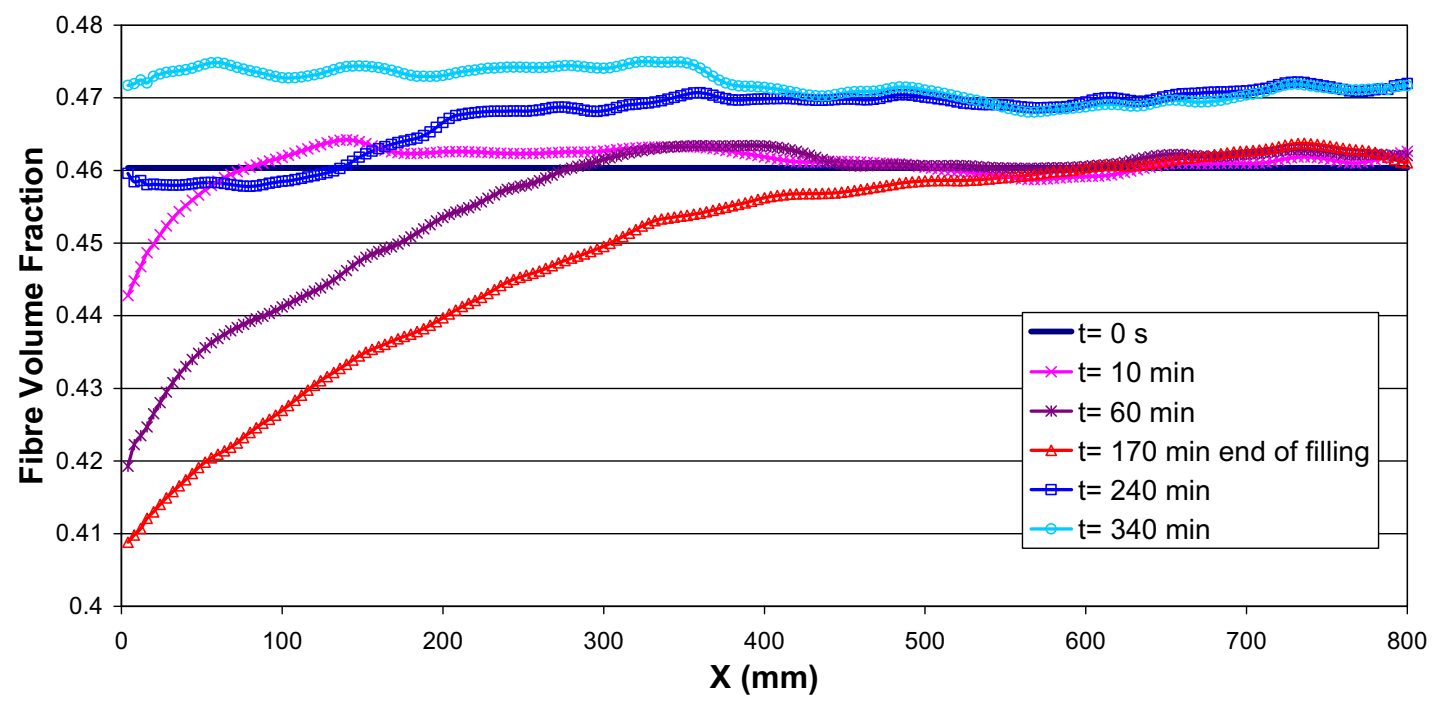

Fig. 13. Variation of $V_{\mathrm{f}}$ along the laminate for the standard experiment.

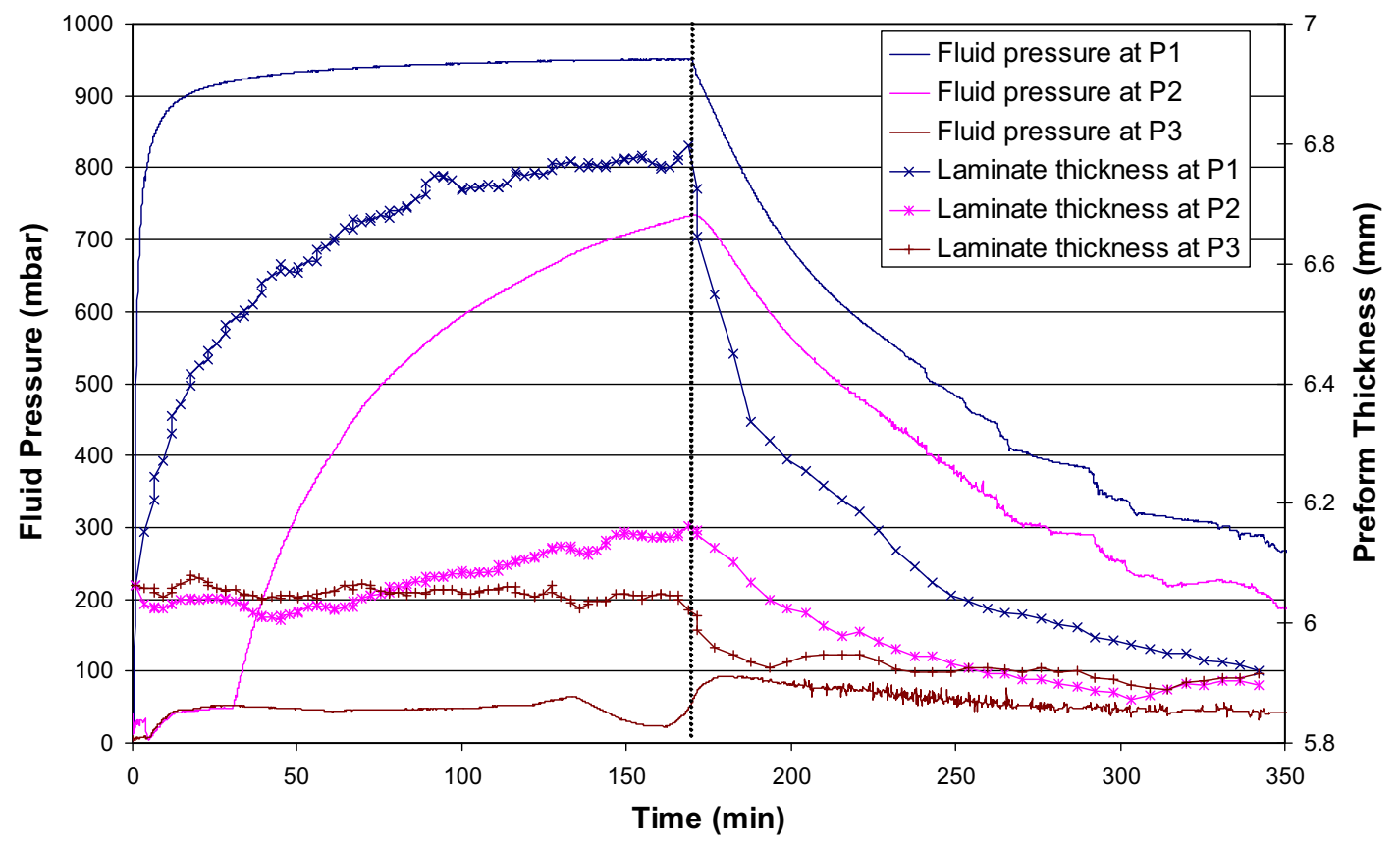

Fig. 14. Evolution of fluid pressure and laminate thickness during the standard experiment. 
$\pm 0.05 \mathrm{~mm}$ for the system in this configuration. Reducing the measuring field, by lowering the cameras or using a longer focal length lens, would increase the accuracy if required.

\subsection{Resin flow rate and front speed measurement}

Resin flow rate was measured via a Mettler Toledo SB16001 mass balance, monitoring the weight of the resin pot. The balance is connected to the data acquisition computer, and the acquisition rate is $1 \mathrm{~Hz}$. The resin flow front was monitored visually through two $20 \mathrm{~mm}$ wide clear strips in the vacuum bag, running along the edge of the laminate. Advancement of the flow is monitored in the captured images, enabling calculation of the flow front velocity. The advantage of using two strips is that the presence of race-tracking along the edges of the preform can be detected.

\section{Experimental programme}

To demonstrate the experimental facility, this paper presents four initial experiments. The influence of the following factors on Resin Infusion was demonstrated: fluid viscosity, the presence of flow enhancing media, and architecture of the reinforcement.

To maximise repeatability a strict experimental procedure has been developed. Prior to the experiment the test fluid and reinforcement are heated to $30^{\circ} \mathrm{C}$ in an environmental chamber, while the mould is heated to the same temperature. The preform is then laid on the mould as depicted in Fig. 7a, and the consumables positioned. The cavity is then closed with the vacuum bag and sealed with tacky tape. The test fluid is then placed in a thermally insulated container on the mass balance and the inlet tube is connected to the container. The inlet tube is then clamped, and the cavity evacuated. After ensuring a proper seal without any leaks, the cavity is left under full vacuum for five minutes (pre-filling). The inlet tube is then released to start the filling stage. Once the fluid reaches the end of the preform, the inlet is clamped and the vent is left at full vacuum during the post-filling period.

\subsection{Material}

\subsubsection{Reinforcement}

Two fibre reinforcements have been employed. An E-glass biaxial $0-90^{\circ}$ stitched fabric weighing $800 \mathrm{~g} / \mathrm{m}^{2}$ (EB800-1270) supplied by High Modulus (NZ) was used for most experiments. To demonstrate the influence of reinforcement architecture, a $480 \mathrm{~g} / \mathrm{m}^{2}$ continuous filament mat (CFM) was used, as supplied by Aurora Glass Fibre.

\subsubsection{Fluid}

Two different test fluids have been used. A mineral oil was chosen having viscosity similar to an infusion grade epoxy resin, with the advantage of maintaining Newtonian behaviour. A Mobil DTE AA was used for the majority of the experiments, while a DTE heavy grade was used to demonstrate the influence of a lower viscosity. The viscosity of these oils and a non-catalysed Nuplex R300 infusion grade epoxy resin are plotted against temperature in Fig. 5.

\subsubsection{Consumables}

To distribute the resin evenly across the width of the mould, $8 \mathrm{~mm}$ diameter silicone Omega flow lines were used at both the inlet and vent. The peel ply (PP80-760) and high temperature grade vacuum bag were supplied by High Modulus (NZ).

\subsection{Plan of experiments}

Table 1 presents the experimental plan, listing the parameters varied from experiment to experiment. All other parameters (temperature, pre-filling conditions, pressures, etc.) were kept constant. Key results from each experiment are presented in Table 2, including initial laminate thickness, initial and final average $V_{\mathrm{f}}$, and filling time.

\subsection{Experiment 1: standard infusion}

Experiment 1 was a linear infusion using the stitched fabric without any flow enhancing medium. A purely 1D flow was estab-

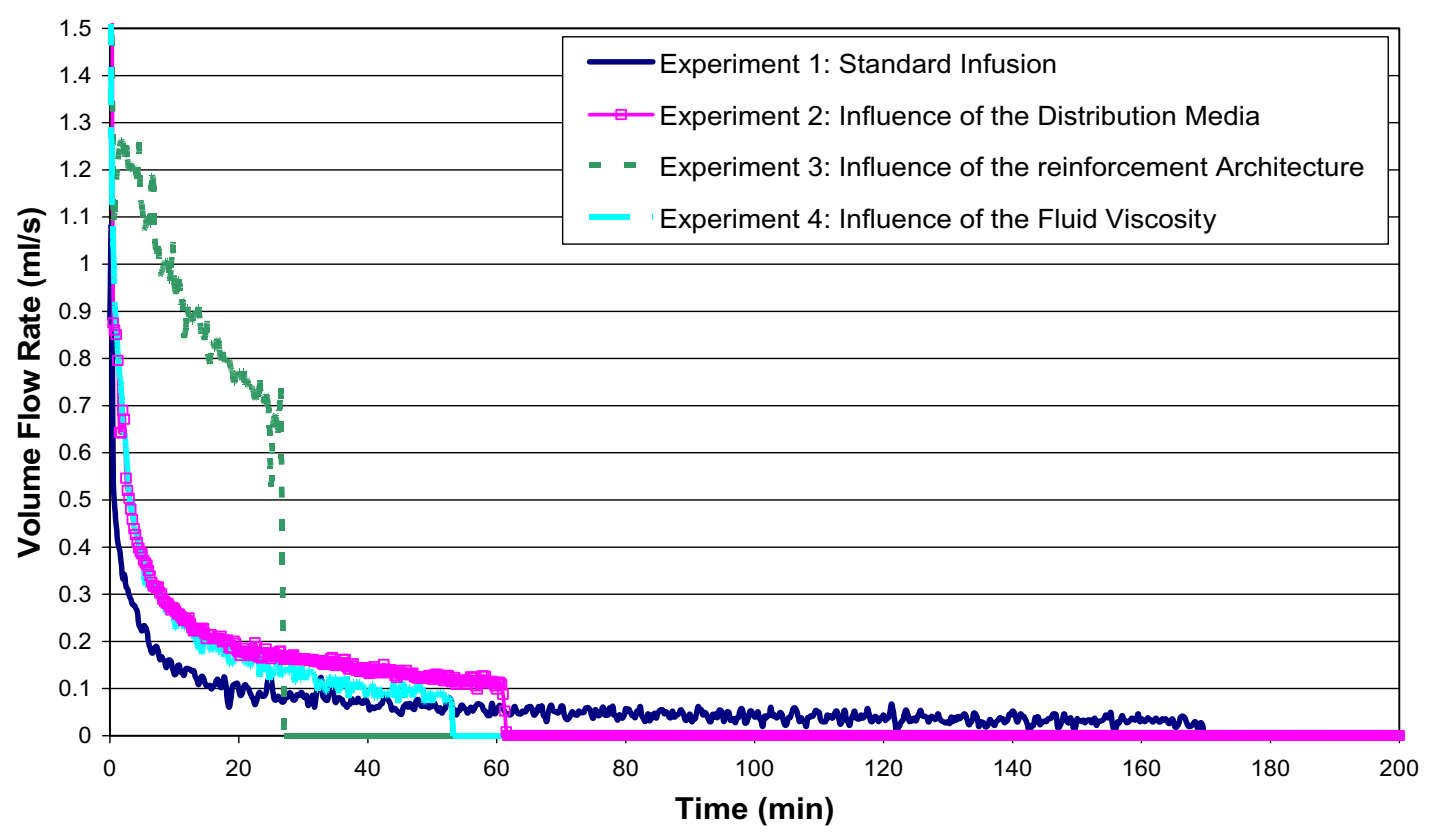

Fig. 15. Comparison of the flow rate for the four experiments. 
lished, no flow occurring through the laminate thickness. This infusion strategy is employed when a reinforcing fabric has high permeability, or when channels within a foam core are used to quickly distribute resin. It also has relevance to an RTM process using inflatable bladders as mould surfaces. Fig. 11 presents full field thickness deviations at four key instants. Fig. 11a presents a map of laminate thickness prior to infusion, Fig. 11b the thickness variation halfway through filling when the flow front has reached $x=400 \mathrm{~mm}$, Fig. 11c the thickness distribution at the end of filling, and Fig. 11d thickness at the completion of post-filling. Fig. 11b and $\mathrm{c}$ show significant thickness changes with a maximum increase of $0.7 \mathrm{~mm}$, a $11.5 \%$ increase in thickness. During post-filling, the thickness reduced by approximately $0.1 \mathrm{~mm}$ as compared to the initial state.

To present evolution of laminate thickness along the length of the mould in a single plot, thickness is averaged across the width of the preform. Fig. 12a presents the evolution of thickness along the mould during the filling and post-filling stages. Fig. 12b pre- sents evolution of $V_{\mathrm{f}}$ in a similar manner, as calculated from Eq. (9). Knowledge of $V_{\mathrm{f}}$ distribution in time can be used to infer the resulting variation in reinforcement permeability. Fig. $12 \mathrm{c}$ presents the evolution of the reinforcement permeability, as calculated using Eq. (10). Data was gathered from preliminary permeability experiments $(d=11 \mu \mathrm{m}, n=2.8$, and $k=0.124)$, and these values are to be taken as a qualitative indication of the magnitude of permeability variation. Fig. 13 plots $V_{\mathrm{f}}$ over the length of the preform at various instances during processing. Knowledge of $V_{\mathrm{f}}$ distribution in time can be used to infer the resulting variation in reinforcement permeability. Fig. 12 clearly shows that most of the thickness and $V_{\mathrm{f}}$ changes occur in the inlet half of the mould. At the end of filling, thickness near the inlet reduces very quickly. As post-filling progresses, the rate of reduction falls.

Fig. 14 presents the fluid pressure evolution at the three transducers, along with laminate thickness measured at the same position (averaged across the laminate width). During filling, pressure near the inlet $\left(P_{1}\right)$ rises rapidly towards a value of 950 mbar. The
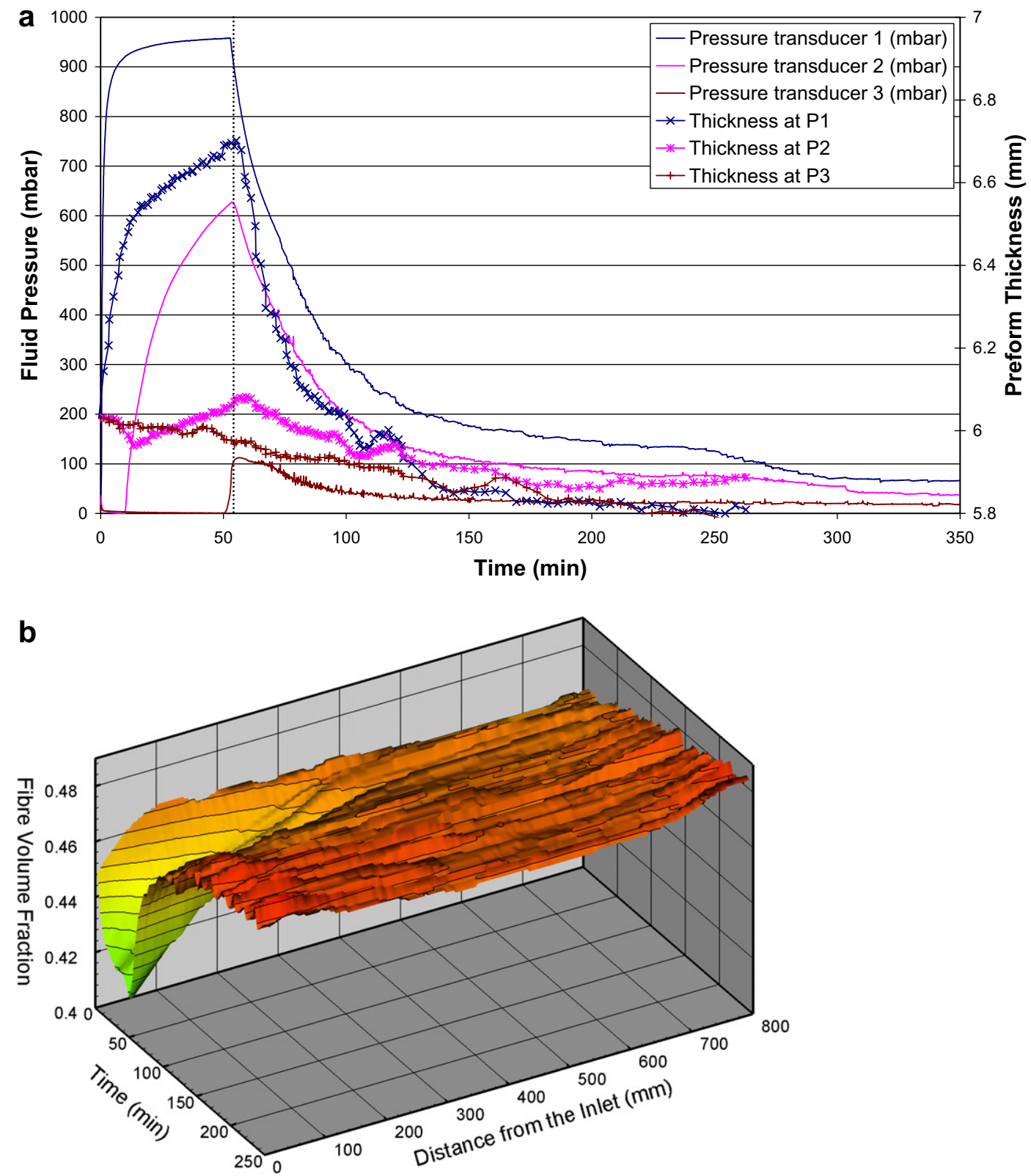

Fig. 16. (a) Evolution of fluid pressure and laminate thickness during experiment 2 and (b) evolution of the fibre volume fraction. 
difference between $P_{1}$ and atmospheric pressure can be attributed to the height difference between the resin pot and the mould, and pressure loss through the inlet tubing and the first $5 \mathrm{~mm}$ of the preform. The pressure at $P_{2}$ rises more slowly to a maximum of 725 mbar. The pressure at $P_{3}$ increases slightly as the fluid arrives, but does not reach 100 mbar as the inlet was clamped to end the filling period. Increasing fluid pressure decreases local reinforcement compaction stress, allowing increases in preform thickness. Halfway through filling, thickness at the inlet had increased by $0.5 \mathrm{~mm}$, resulting in a $V_{\mathrm{f}}$ drop from 0.46 to 0.42 . Just behind the flow front a small thickness drop is observed, due to the fluid lubricating effect reducing the reinforcement compaction resistance $[14,19,23]$. However, this effect is limited with the stitched fabric and will account for negligible changes in $V_{\mathrm{f}}$ and permeability. As the flow front approaches the vent, thickness at the inlet has increased to $6.8 \mathrm{~mm}$ (initially $6.06 \mathrm{~mm}$ ), relating to a $V_{\mathrm{f}}$ of 0.418 . Such decreases in $V_{\mathrm{f}}$ will significantly change the local permeability of the laminate. During post-filling, thicknesses and pressures gradually reduce. After a period similar in length to the filling time, thicknesses have stabilised and the $V_{\mathrm{f}}$ is $\sim 0.47$ along the preform length. A significant pressure gradient still exists along the mould ranging from $280 \mathrm{mbar}$ at $P_{1}$ to $50 \mathrm{mbar}$ at $P_{3}$. The reader should take note of the long post-filling period, during which a thermoset resin may gel.

Fig. 15 presents the flow rate evolution measured during filling for all four experiments. The data for all three experiments using the stitched fabric show similar trends. As expected, utilising a distribution media, or reducing fluid viscosity resulted in significantly higher flow rates. Considering total volume of fluid injected, both the 'standard' and 'low viscosity' experiments consumed similar quantities (686 $\mathrm{ml}$ and $676 \mathrm{ml}$ respectively). The experiment using distribution media consumed $789 \mathrm{ml}$, this difference being very close to the porous volume of the distribution media layer. Due to the much greater porosity and permeability of the CFM, higher flow rates are maintained to the completion of filling, and a total of $1529 \mathrm{ml}$ was consumed.
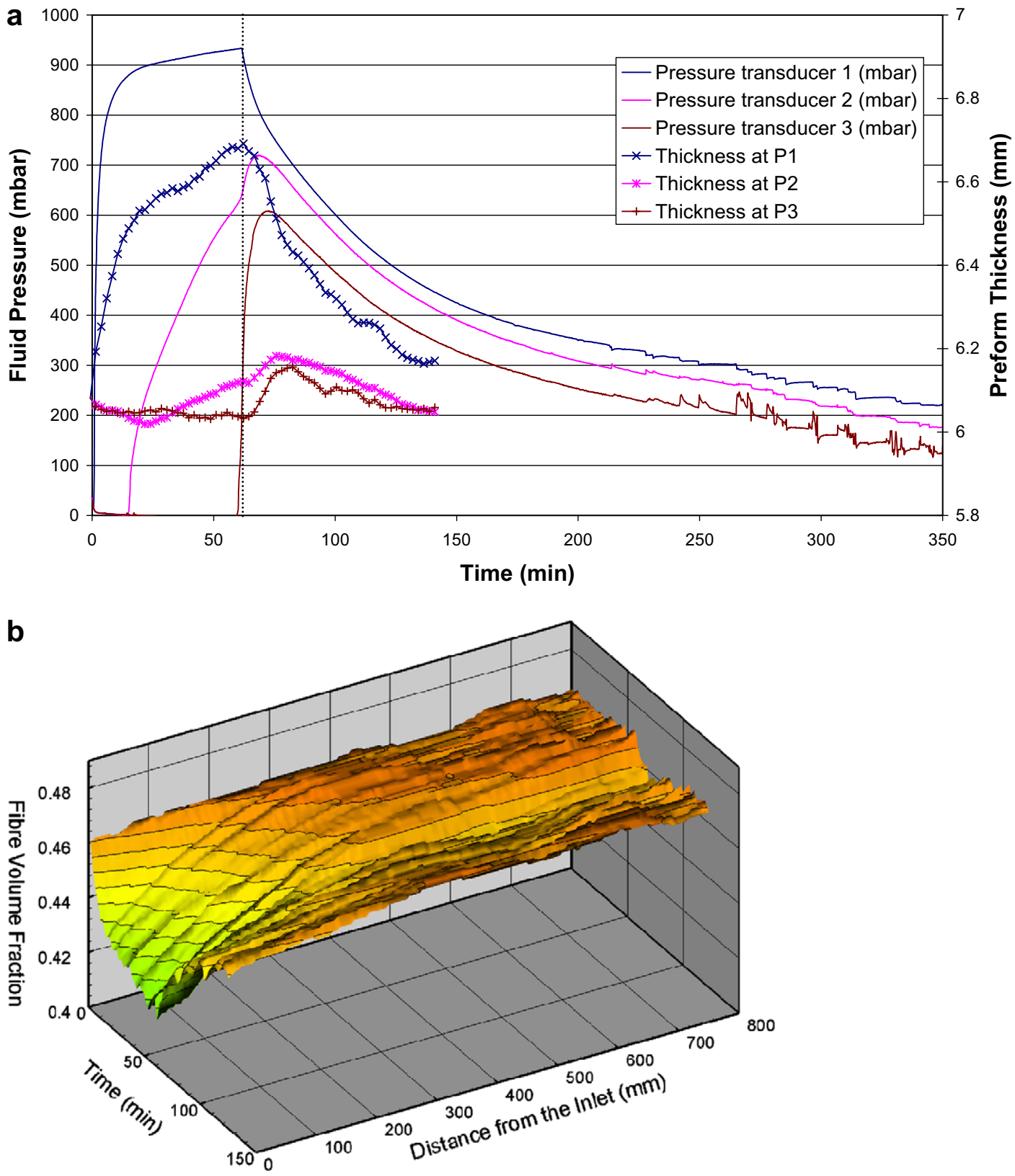

Fig. 17. (a) Evolution of fluid pressure and laminate thickness during experiment 3 and (b) evolution of the fibre volume fraction. 


\subsection{Experiment 2: influence of fluid viscosity}

To demonstrate the effect of fluid viscosity, experiment 1 was repeated using a lower viscosity oil. The oil used in all other experiments has a viscosity of 0.521 Pa s at $30^{\circ} \mathrm{C}$. The Mobil DTE Heavy oil used during this experiment has a viscosity of $0.144 \mathrm{~Pa} s$ at $30{ }^{\circ} \mathrm{C}$. The resulting fill time was $53 \mathrm{~min}$, approximately three times faster than experiment 1 . A similar observation can be made with regards to the post-filling stage.

Fig. 16a presents the evolution of fluid pressure and preform thickness at position $P_{1}, P_{2}$, and $P_{3}$. During filling, pressure and thickness vary in a similar manner as for experiment 1 , but over a shorter time period. Fig. $16 \mathrm{~b}$ presents $V_{\mathrm{f}}$ evolution with time along the laminate length. $V_{\mathrm{f}}$ at the inlet decreased from 0.462 to 0.419 during filling. During post-filling, pressures and thicknesses reduced relatively quickly. The general fluid pressure and pressure gradient through the length of the preform are much smaller than during experiment 1 , ranging at the end of post-filling from 75 mbar at $P_{1}$ to 25 mbar at $P_{3}$. Final $V_{\mathrm{f}}$ is slightly higher than that observed for experiment 1 at 0.476 . These differences can be explained by the longer time available for post-filling. For the range of fluid viscosity considered, general preform behaviour during processing is unaffected. However the faster filling achieved with a lower viscosity fluid allows more time during post-filling for equilibrating fluid pressure along the preform length, and increasing compaction of the reinforcement before gelation of the resin.

\subsection{Experiment 3: influence of distribution media}

When distribution media is placed on top of the reinforcement, fluid flow is predominantly through the thickness of the laminate. Fluid flows along the distribution media, and then through the thickness of the preform. Larger differences between the in-plane permeability of the flow enhancing medium and reinforcement result in more significant through thickness flow [39]. For this experiment a time difference was noted between the passing of the flow front over each pressure transducer, and the increase of resin pressure measured. This is due to the difference between the arrival time of the fluid in the distribution media, and arrival of the fluid at the mould surface. The lag distance between the top and bottom flow front remained constant once the top flow front had pro- gressed past the first $50 \mathrm{~mm}$. The fill time was $62 \mathrm{~min}$, almost three times faster than the experiment without distribution media.

Fig. 17a presents the variation of fluid pressure and laminate thickness at $P_{1}, P_{2}$, and $P_{3}$. Laminate thickness has been calculated by removing the thickness of the distribution media and peel ply from the total measured thickness. Fig. $17 \mathrm{~b}$ presents $V_{\mathrm{f}}$ evolution with time along the laminate length. During filling both the thicknesses and pressures evolve in a very similar manner as for experiment 1 . Thickness at the inlet increased by $0.7 \mathrm{~mm}$, resulting in a reduction of $V_{\mathrm{f}}$ from 0.46 to 0.416 . As for experiment 1 , a very small dip in thickness was noticeable behind the flow front. Compared to experiment 1 , the thickness reduction behind the flow front is slower and more gradual, due to through thickness flow of the resin. While these thickness variations are significant, they may be less influential on effective in-plane preform permeability, which is significantly influenced by the distribution media permeability. At clamping of the inlet there is a rise in both pressure and thickness at positions $P_{2}$ and $P_{3}$, caused by the fluid pressure equalising through the thickness of the laminate. Beyond this initial rise, pressure and thickness evolve in a similar manner as for the previous experiments. It is noticeable that the pressure gradient was smaller at the end of the post-filling, pressure ranging from $230 \mathrm{mbar}$ at the inlet to 150 mbar near the vent. This is reasonable, as the distribution media provides an easier flow path for the fluid towards the vent. The reader should also note the time taken for pressure and thickness to equilibrate during post-filling, with pressures still varying $300 \mathrm{~min}$ after the completion of filling.

\subsection{Experiment 4: influence of reinforcement architecture}

To demonstrate the influence of significantly different reinforcement architecture, experiment 1 has been repeated using the CFM. In this experiment flow is purely 1D, no flow occurring through the thickness. The fill time was $27.5 \mathrm{~min}$, more than six times faster than experiment 1 using the stitched fabric.

Fig. 18 presents the thickness variation profile in the laminate halfway through filling, highlighting the greater influence fluid lubrication has on the CFM as compared to the stitched fabric (Fig. 11b). Fig. 19a presents the evolution of the fluid pressure and laminate thickness at $P_{1}, P_{2}$, and $P_{3}$. When compared to Fig. 14a, significant differences are highlighted. Fig. 19b presents

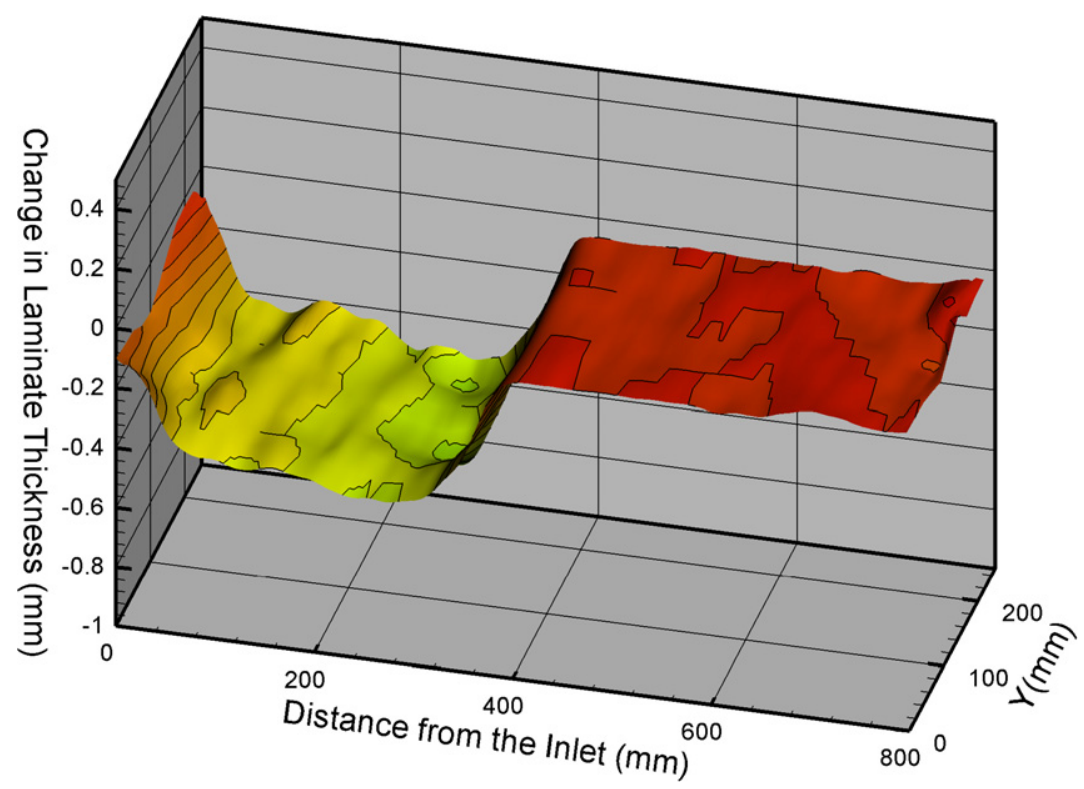

Fig. 18. Thickness distribution profile halfway through the filling of experiment 4 . 
the evolution with time of $V_{\mathrm{f}}$ along the length of the mould. The CFM produces much lower $V_{\mathrm{f}}$ than the stitched fabric, the average value prior to filling being 0.234 . During filling a clear dip in laminate thickness (about $0.5 \mathrm{~mm}$ ) was observed as the flow front progressed, indicating a significant fluid lubrication effect. Within the impregnated laminate, thickness increased slowly as the fluid pressure raised, inlet values reaching the levels established prior to filling. Measured fluid pressures increased at a higher rate than for experiment 1 , but peaked at smaller values. For example, $P_{1}$ peaked at 650 mbar.

During post-filling, fluid pressure equalised rapidly throughout the length of the preform. Fluid pressure then slowly dropped to 20 mbar, over a period much longer than the filling stage. During this extended post-filling period, thicknesses fell to levels well below those existing during filling, and significant thickness gradients were observed along the mould. After $175 \mathrm{~min}$ of post-filling, the $V_{\mathrm{f}}$ varied from 0.26 to 0.28 between the vent and the inlet. While demoulding it was observed that significant porosity was generated near the inlet, too much fluid being removed from the laminate.

\section{Conclusion}

The Resin Infusion process monitoring system developed at the University of Auckland measures a wide range of experimental parameters during both filling and post-filling. A feature of the system is the purpose built stereophotogrammetry unit, capable of capturing full field laminate thickness data at $0.2 \mathrm{~Hz}$. Full field fibre volume fraction can be monitored dynamically throughout the process, which allows calculation of the transient changes in local permeability throughout the preform. In combination with resin pressure and flow rate measurements, a large amount of data is available for comparison with simulation.

Four experiments were presented as a demonstration of the system capabilities, and to demonstrate the influence of certain parameters. In all cases utilising the biaxial stitched fabric significant increases in thickness were measured during filling, resulting in decreases in volume fraction on the order of $10 \%$ from the initial 0.46. Fluid pressure and thickness varied significantly through both filling and post-filling, though the changes during the post-filling period typically happened on a larger time frame.
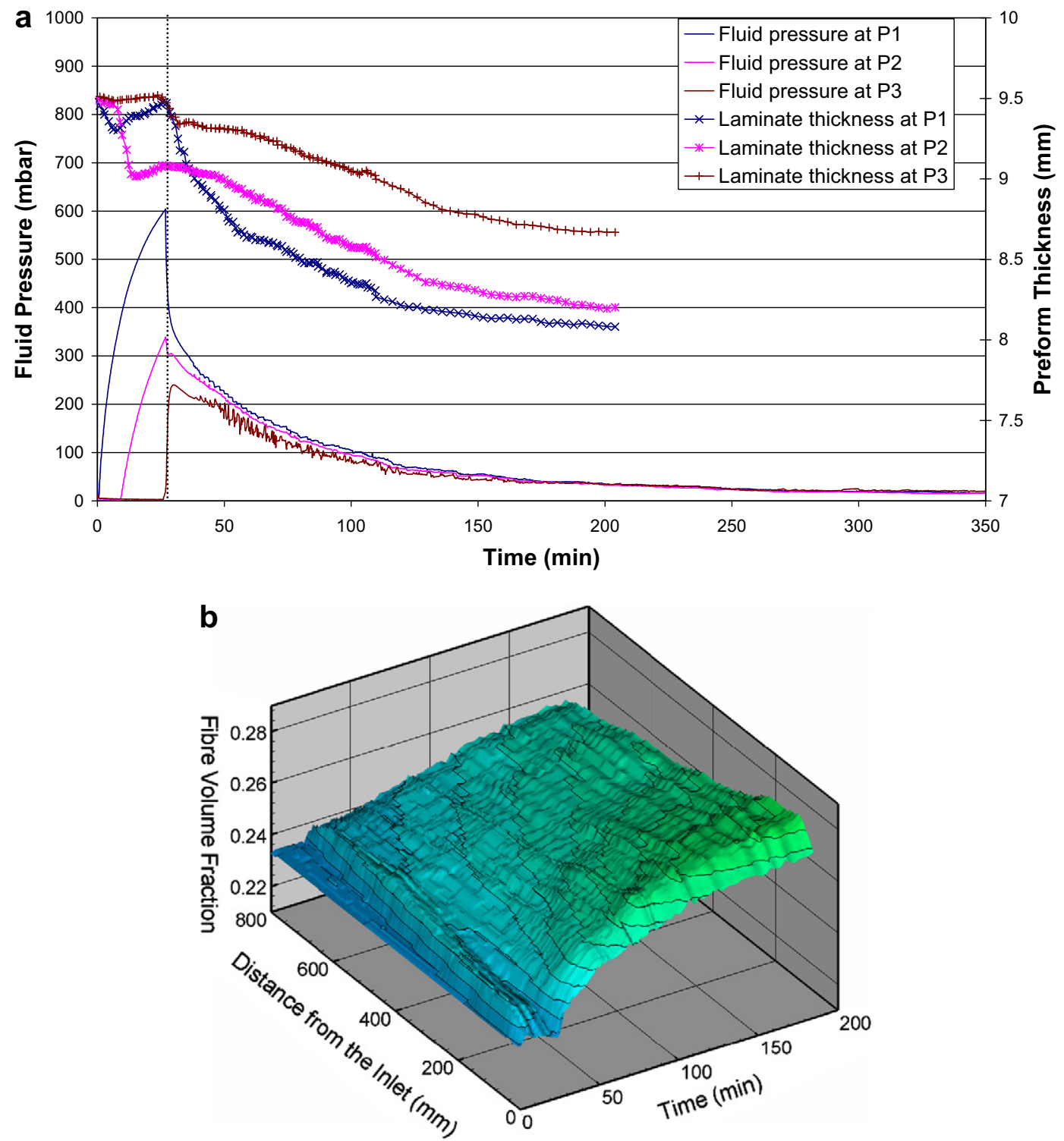

Fig. 19. (a) Evolution of fluid pressure and laminate thickness during the CFM experiment and (b) evolution of the fibre volume fraction. 
Use of a distribution media significantly decreased fill time, while pressure and thickness varied in a similar manner. The pressure gradients were reduced along the mould during post-filling, though the pressure levels reduced at a similar rate as for the experiment without distribution media. A reduction in viscosity also reduced fill time, essentially compressing the time scale relative to the standard experiment. The CFM reinforcement represents a significant difference to the stitched fabric used in all other experiments. As expected the fill time was greatly reduced, and significantly higher fluid flow rates were measured. This reinforcement produced a larger drop in thickness behind the flow front, and further thickness reductions during the post-filling stage. The large differences in fluid pressure and laminate thickness distribution between the end of filling and the end of post-filling emphasises the importance of including the post-filling stage in an RI simulation. It is during the post-filling that the part reaches its final quality, and it is therefore important to know how to control that part of the process.

\section{Acknowledgements}

The authors would like to acknowledge the generous support of the Foundation for Research, Science and Technology, New Zealand. We would also like to thank High Modulus (NZ), Nuplex Industries Ltd. and Aurora Glass Fibre (NZ) Ltd. for their support of this research.

\section{References}

[1] Berenberg B. Liquid composite molding achieves aerospace quality. HighPerform Compos 2003;11(6):18-22.

[2] Lawrence JM, Fried P, Advani SG. Automated manufacturing environment to address bulk permeability variations and race tracking in resin transfer molding by redirecting flow with auxiliary gates. Compos Part A: Appl Sci Manufact 2005;36(8):1128-41.

[3] Gokce A, Advani SG. Simultaneous gate and vent location optimization in liquid composite molding processes. Compos Part A: Appl Sci Manufact 2004;35(12):1419-32.

[4] Lin M, Thomas Hahn $\mathrm{H}$, Huh $\mathrm{H}$. A finite element simulation of resin transfer molding based on partial nodal saturation and implicit time integration. Compos Part A: Appl Sci Manufact 1998;29:541-50.

[5] Soukane S, Trochu F. New remeshing applications in resin transfer molding. J Reinf Plast Compos 2005;24(15):1629-53.

[6] Mohan RV, Ngo ND, Tamma KK. On a pure finite-element-based methodology for resin transfer molds filling simulations. Polym Eng Sci 1999;39(1):26-43.

[7] Lin RJ, Lee JL, Liou MJ. Mold filling and curing analysis in liquid composite molding. Polym Compos 1993;14(1):71-81.

[8] Liu B, Bickerton S, Advani SG. Modelling and simulation of resin transfer moulding (RTM) - gate control, venting and dry spot prediction. Compos Part A: Appl Sci Manufact 1996;27(2):135-41.

[9] Simacek P, Advani SG. Desirable features in mold filling simulations for liquid composite molding processes. Polym Compos 2004;25:355-67.

[10] Williams C, Summerscales J, Grove S. Resin infusion under flexible tooling (RIFT): a review. Compos Part A: Appl Sci Manufact 1996;27(7):517-24.

[11] Hammami A, Gebart BR. Analysis of the vacuum infusion molding process. Polym Compos 2000;21(1):28-40.

[12] Kang MK, Lee WI, Hahn HT. Analysis of vacuum bag resin transfer molding process. Compos Part A: Appl Sci Manufact 2001:32-1560.

[13] Correia NC, Robitaille F, Long AC, Rudd CD, Simacek P, Advani SG. Analysis of the vacuum infusion moulding process: I. Analytical formulation. Compos Part A: Appl Sci Manufact 2005;36(12):1645-56.

[14] Andersson HM, Lundstrom TS, Gebart BR. Numerical model for vacuum infusion manufacturing of polymer composites. Int J Numer Methods Heat Fluid Flow 2003;13(3):383-94.
[15] Acheson JA, Simacek P, Advani SG. The implications of fiber compaction and saturation on fully coupled VARTM simulation. Compos Part A: Appl Sci Manufact 2004;35:159-69.

[16] Walsh SM, Freese CE. Numerical model of relaxation during vacuum-assisted resin transfer molding (VARTM). Polym Compos 2005;26(5):628-35.

[17] Kessels JFA, Jonker AS, Akkerman R. Fully 2 1/2D flow modeling of resin infusion under flexible tooling using unstructured meshes and wet and dry compaction properties. Compos Part A: Appl Sci Manufact 2007;38(1): 51-60.

[18] Trochu F, Ruiz E, Achim V, Soukane S. Advanced numerical simulation of liquid composite molding for process analysis and optimization. Compos Part A: Appl Sci Manufact 2006;37(6):890-902.

[19] Andersson HM, Lundstrom TS, Gebart BR, Synnergren P. Application of digital speckle photography to measure thickness variations in the vacuum infusion process. Polym Compos 2003;24(3):448-55.

[20] Govignon Q, Bickerton S, Morris J, Lin J. A stereo photography system for monitoring full field thickness variation during resin infusion. In: Proceedings of FPCM8 conference, Douais, France, July 2006. p. 231-9.

[21] Lin Y, Morris J, Govignon Q, Bickerton S. Digital speckle photogrammetry. IVCNZ06, 2006.

[22] Liu J, Delmas PJ, Gimel'farb G, Morris J. Stereo reconstruction using an image noise model. In: Proceedings of digital image computing: techniques and application (DICTA2005) conference, Cairns, Australia, December 2005.

[23] Daval B, Bickerton S. Exploring the potential for laminate quality control using VARTM. In: Proceedings of 36th international SAMPE technical conference, San Diego, CA, 15-18 November 2004.

[24] Govignon Q, Allen T, Bickerton S, Morris J. Monitoring variations in laminate properties through the complete resin infusion process. In: Proceedings of SAMPE: from art to science: advancing materials and process engineering conference, Cincinnati, OH, October 29-November 1, 2007. CD-Rom 18p.

[25] Pearce N, Summerscales J. Compressibility of a reinforcement fabric. Compos Manufact 1995;6(1):15-21.

[26] Robitaille F, Gauvin R. Compaction of textile reinforcements for composites manufacturing. I: review of experimental results. Polym Compos 1998;19:198-216

27] Saunders RA, Lekakou C, Bader MG. Compression and microstructure of fibre plain woven cloths in the processing of polymer composites. Compos Part A: Appl Sci Manufact 1998;29(4):443-54

[28] Chen B, Chou T-W. Compaction of woven-fabric preforms in liquid composite molding processes: single-layer deformation. Compos Sci Technol 1999;59(10):1519-26.

[29] Chen B, Chou T-W. Compaction of woven-fabric preforms: nesting and multilayer deformation. Compos Sci Technol 2000;60(12-13):2223-31.

[30] Hammami A. Effect of reinforcement structure on compaction behavior in the vacuum infusion process. Polym Compos 2001;22(3):337-48.

[31] Bickerton S, Buntain MJ, Somashekar AA. The viscoelastic compression behavior of liquid composite molding preforms. Compos Part A: Appl Sci Manufact 2003;34(5):431-44

[32] Grimsley BW, Cano RJ, Hubert P, Loos AC, Kellen CB, Jensen BJ. Preform characterization in VARTM process model development. In: Proceedings of 36th international SAMPE technical conference, San Diego, CA.

[33] Comas-Cardona S, Le Grognec P, Binetruy C, Krawczak P. Unidirectional compression of fibre reinforcements. Part 1: a non-linear elastic-plastic behaviour. Compos Sci Technol 2007;67(3-4):507-14.

[34] Somashekar AA, Bickerton S, Bhattacharyya D. Exploring the non-elastic compression deformation of dry glass fibre reinforcements. Compos Sci Technol 2007;67(2):183-200

[35] Robitaille F, Gauvin R. Compaction of textile reinforcements for composites manufacturing. II: compaction and relaxation of dry and $\mathrm{H}_{2} \mathrm{O}$ saturated woven reinforcements. Polym Compos 1998;19:543-57.

[36] Saunders RA, Lekakou C, Bader MG. Compression in the processing of polymer composites 2. Modelling of the viscoelastic compression of resin-impregnated fibre networks. Compos Sci Technol 1999;59:1483-94.

[37] Grimsley BW, Hubert P, Song X, Cano RJ, Loos AC, Pipes RB. Flow and compaction during the vacuum assisted resin transfer molding process. SAMPE, 2001.

[38] Williams CD, Grove SM, Summerscales J. The compression response of fibrereinforced plastic plates during manufacture by the resin infusion under flexible tooling method. Compos Part A: Appl Sci Manufact 1998;29(12):111-4.

[39] Han K, Jiang S, Zhang C, Wang B. Flow modeling and simulation of SCRIMP for composites manufacturing. Compos Part A: Appl Sci Manufact 2000;31(1):79-86 